\title{
Julio Cortázar: al Unísono y al Dísono*
}

1.1. Arte subversivo: violación de los límites de las ideologías represivas: develar lo que las cristalizaciones ideológicas ocultan: desobedecer el código social impuesto por un orden punitivo y censorio: desoir la razón de Estado: rebasar lo permisible: transgredir lo decible.

1.2. Cortázar: contravención inveterada: obstinado anticonformismo: guerra al establishment. Rebelión contra la Gran Costumbre: "negar toda lo que el hábito lame hasta darle suavidad satisfactoria": constante ruptura de la normalidad conveniente, concordadora, consentida, convenida, consuetudinaria: "Negarse a que el acto delicado de girar el picaporte, ese acto por el cual todo podría transformarse, se cumpla con la fría eficacia de un reflejo cotidiano.": romper las paredes de lo consabido, lo preparado, lo resuelto, lo programado: "abrirse a la novedad potencial de cada instante".

1.3. Tergiversar las prácticas usuales, las finalidades admitidas, las funciones pragmáticas: Ocupaciones raras: tareas excéntricas, no utilitarias, lúdicas, pero sistemáticas (remedo de los trabajos "serios"), donde el proceso, el proceder es más importante que los resultados: objetivos que no se inscriben en los decálogos razonables: búsqueda de lo sorpresivo y sorprendente: la gratuidad como máxima disponibilidad frente a lo imprevisible.

* Fuentes de donde fueron extraidas las citas, todas de Cortázar:

HCF Historia de Cronopios $y$ de famas (Buenos Aires: Ediciones Minotauro, 1962).

LVM La vuelta al dia en ochenta mundos (México: Siglo XXI, 1967).

PO Prosa del observatorio (Barcelona, Lumen, 1972).

R Rayuela (Buenos Aires: Sudamericana, 1963).

UR Ultimo round, Siglo XXI, México, 1969.

Indicaciones de parágrafo, obra y número de página:

1.2: HCF, 12 y 11. 1.5: PO, 7. 3.3.: R, 377. 4.1: UR, 37. 4.5: LVM, 18. 6.1: LVM, 67. 6.4: IVM: 49. 10.3: UR, 38. 10.7: UR, 41. 10.10: LVM, 7. 11.1: UR, 29. 13.7: UR, 31. 14.4: UR, 213. 14.5: UR, 208. 14.11: $R, 560$. 15.1: UR, 217. 15.2: $R$, 544. 15.3: $R, 544$ y 602. 16.2: UR, 60. 17.2: UR, 201. 17.5: UR, 213. 
1.4. Cubicar la esfera, posar tigres, tender hilos, dejar caer un pelo en el lavabo y recuperarlo: actividades abiertas, aleatorias: ceremonias iniciáticas que ponen a los participantes en contacto con lo inclasificable: acciones tendientes a probar lo precario de la estabilidad, del statu quo, de lo real convenido: la causalidad previsible es reemplazada por las excepciones, azares e improbabilidades.

1.5. Apertura a otras posibilidades operativas: revelación de lo intersticial ("esa manera de estar entre, no por encima o detrás sino entre"): acceso a otras dimensiones.

2.1. Sorpresa osmótica que se infiltra paulatinamente. Sorpresa: desfasaje, desajuste, descolocación: desconcierto de un texto que introduce cada vez más incertidumbres: extrañamiento: pasaje de lo sólito o lo insólito.

2.2. Cuento: arco que se va tensando para lanzar la flecha lo más lejos posible. Tensión narrativa proporcional al avance del extrañamiento: creciente inestabilidad semántica: plurivalencia: evidencias ininteligibles: lo enigmático, pero irresoluto: ni esotérico ni exotérico.

2.3. Cuando se sale itrecuperablemente del sistema de la causalidad natural, empírica, de lo probable: ingreso en lo maravilloso. Ruptura recuperable, que por fin se explica mediante las pautas que rigen la experiencia objetiva: entropía momentánea que no altera el sistema: realismo. Entre medio, el oscilante territorio de Cortázar.

2.4. Lo fantástico: pasaje a otro orden con su propia coherencia: ni banalidad ni mera extravagancia: tanto rigor como en el juego: dominio de las fuetzas extrañas que nos involucran en un desconocido mosaico, en una figura concertadora (cortazadora) de varios destinos ilusoriamente desligados, que enhebra actos aparentemente autónomos

2.5. La escritura se propone "acorralar lo fantástico en lo real, realizarlo".

3.1. Concepción mágica del mundo: la visión de la realidad como irreductible, ineludiblemente misteriosa. Piel legible, piel decible, entranas escrutables pero ininteligibles, inefables. Epidermis provisoria y precariamente codificable. Realidad profunda: la determinante, la decisiva: 
evidencia intuitiva (conocimiento simpatético, sensosentimental) sólo verbalizable por alusión: realidad vislumbrada a través de señales intermitentes, anuncios repentinos, mensajes cifrados: no puede interpretarse por vía intelectiva, analítica, kantiana, sino mediante una apertura-entrega capaz de superar las categorías lógicas: vía supralógica: por medio de una ampliación de la capacidad perceptiva, por un acrecentamiento de la experiencia posible.

3.2. Escribir: inventar un mandala, purificarse. Para acceder a la zona: escribir en trance, en una determinada longitud, con swing. Escritura: un arma secreta.

3.3. Tradición romántica-simbolista-surrealista: poeta intermediario de las fuerzas ocultas, vidente alucinado, oracular: tabla rasa: vuelta a la plenitud del comienzo: regreso al útero: nostalgia del edén. La verdadera condena: "el olvido del Edén, es decir, la conformidad vacuna, la alegría barata y sucia del trabajo y el sudor de la frente y las vacaciones pagas."

3.4. Retorno a la percepción virginal del adamita o a sus equivalentes actuales: niño y loco: disparadas por vía de la fantasía ingenua: visión infantil, candorosa, que ve sin prejuicios, con constante voluntad de asombro: sacar lo visto de la textura adulta: tasadora, clasificadora, congeladora, solidificante ( $=$ "edificante").

3.5. Los piantados: aledaños de la cordura: arrabales de la literatura: la visión excéntrica: el desfasaje que revela otras dimensiones censuradas por la codificación convencional: los heteróclitos no sujetos a las pautas razonables.

3.6. Ser piantado no es una salida, sino una llegada: locura romántica: locura enaltecida sin experiencia real de la demencia (disolución de la personalidad, caos, anulación, caída definitiva en el gran agujero negro, muerte mental, desequilibtio aniquilador).

4.1. Escribir: exorcisar: rechazar invasores posesivos: "productos neuróticos, pesadillas a alucinaciones neutralizadas mediante la objetivación": excitación neurótica: coherencia neurótica: discurso desflecado, fisurado, descentrado: discurso enmarañado por la incongruencia enriquecedora que rompe todo ordenamiento abstracto, toda regularidad: Cuello de gatito negro. 
4.2. Literatura y neurosis. Literatura: catarsis de obsesiones traumáticas: liberación: psicoterapia: psicologización del relato: relación apasionada, patética, visceral con lo narrado. Narración: mensaje conmovedor: mensaje perturbador que exige una adhesión de intimidad: intimación emotiva: lo contrario de Kafka o Borges: clásicos: distanciamiento, despersonalización de la anécdota, estilo menos expresivo (menos expresionist2).

4.3. Psicologización del mensaje: tendencia a lo psicopatológico (antecedente: la neurastenia modernista): sugestión por enrarecimiento: irrupción de la anormalidad: mayor contacto con las zonas oscuras (lo onirico, inconsciente, demencial, instintivo, demoníaco): tendencia al desequilibrio anímico: visión disgregadora: opósitos irreconciliables: conciencia escindida, atormentadora: inquietud, insatisfacción, desasosiego: neurosis.

4.4. La incertidumbre se instala en el interior del discurso desbaratado la univocidad: desmantelamiento de la coherencia discursiva, de la seguridad semántica: inestabilidad, indeterminación, conflicto pasan de la connotación a la denotación: el discurso narrativo se contagia del poético.

4.5. $\mathrm{L}_{2}$ realidad posible, por su incompatibilidad con la deseada, se vuelve dominio del sin sentido y la nonada: absurdo negativo. Absurdo positivo: ininteligibilidad de la realidad última, basamental, percibida por vías no intelectivas: "un claro sentimiento del absurdo nos sitúa mejor y más lúcidamente que la raíz kantiana."

4.6. Tradición romántico-simbolista: identificación de anormalidad con originalidad: rareza, extravagancia, insensatez, irregularidad, excentricidad son antídotos contra lo acostumbrado, lo razonable, lo común, lo anodino, lo tradicional. La explicitud y clarividencia del discurso apolíneo son desbaratadas por el desarreglo de los sentidos, por la alquimia verbal: visión cada vez más agitada y fragmentaria: Rayulela.

4.7. Tradición romántica-simbolista-surrealista: antimaquinismo, anticientificismo, antitecnología: tabla rasa: afán de despojarse de la acumulación científica, técnica y artística atesorada por el hombre: volverse bárbaro: desculturación o por lo menos poda del exceso castrador de La cultura: intento de anular los poderes paralizadores de la tradición occidental. 
5.1. Contrapartida cortazariana: disparadas por vía erudita, por la cultura magna y la estética monumental: gran paquete de civilizaciones, músicas, ciudades, libros, cuadros encarnados en presencias tan presentes como las humanas. Oscilación irresoluta: tabla rasa vs. Kultur.

5.2. Mezcla de tiempos históticos (Todos los fuegos el fuego, El otro cielo), de categorías culturales (Rayuela), de niveles literarios c idiomáticos (La vuelta al dia en ocbenta mundos, Ultimo rosmd) : universalidad irreverente:

6.1. "El tiempo de un escritor: diacronía que basta por sí misma para desajustar toda sumisión al tiempo de la ciudad. Tiempo de más adentro o de más abajo: encuentros en el pasado, citas del futuro con el presente, sondas verbales que penetran simultáneamente el antes y el ahora y los anulan."

6.2. Tiempo externo y tiempo intimo: los textos avanzan y retroceden porque la cronología de su aparición (fenotexto) no es la misma que la de su gestación (genotexto). Después de Rayuela surgen cuentos que son como supervivencias postergadas, como desprendimientos guardados de libros anteriores.

6.3. Salir del tiempo y del espacio euclideanos, galileicos, newtonianos: salir de la cronología y la topología instauradas por el consenso social, por la rutina perpetua repetidora: contravenir las categorías usuales del entendimiento, la conciencia codificadora.

6.4. Puerta o pasaje: el humor: libre arbitrio para alterar el sistema de restricciones naturales y sociales: superación de lo real empírico: superación de la imaginación reproductora: crítica a los mecanismos de aprehensión convencionales: activante que precipita lo normal en un juego vertiginoso de inesperadas relaciones: "jugar con todo lo que brinca de esa fluctuante disponibilidad del mundo".

6.5. Puerta o pasaje: descalabrar la concatenación episódica, desarticular la coherencia discursiva, descoyuntar la verosimilitud realista: hacer estallar el lenguaje: provocar el gran desbarajuste que posibilite un nuevo ordenamiento (arquetipo mitológico: diluvio: apocalipsis: disolución: regresión a lo preformal: purificación, latencia germinal: nuevo nacimiento). 
6.6 Romper la torpe máquina binaria: conjunciones en vez de disyunciones: puertas abiertas por doquier, puentes, pasajes de ida y vuelta: mutaciones reversibles: máxima plenitud: máxima polisemia: "encuentro ab ovo": convergencia de todos en el centro del Gran Todo: idealismo, euforia panteísta, vitalismo orgiástico, erotismo universalizado.

7.1. Desflorar el idioma: Eros ludens. No hay erótismo sin el ejercicio natural de una libertad ejercida con soltura: para conquistar la libertad sexual hay que conquistar antes todas las otras libertades.

7.2. Erotismo: sexo + cultura: sexo + soltura: sexualidad por encima del ombligo: sexualidad cultivada o culturada.:

7.3. Erotismo: sexo culturado: sexo elaborado: de la sexualidad glandular a la mental: de la sexualidad fisiológica a la universal: del semen al sema.

7.4. Erotismo: mundo de analogías carnalizadas: metáforas copulativas o cópulas omnianalógicas: un mismo arrebato amoroso lo conjuga todo: el mundo movilizado por la pasión copulativa (Breton): la ligadora carnal que todo acoyunta.

7.5. Erotismo: abölición de controles, tabúes, censuras, represiones: sobre todo los hispanoamericanos (es decir, híspánicos): antimachismo. Contra la conciencia pecaminosa: contra la culpabilidad judeocristiana.

7.6. Erotismo: transgresión de las leyes sociales: erotismo subversivo: transgresión de lo decible: el glíglico.

7.6. El idioma castellano, trabado por una tradición de censores inquisitoriales, carece de adecuado registro erótico: es parco, opaco y entumecedor de lo erótico. El erotismo desborda la nominación disponible, vuelve el verbo impulsivo, avasallador, disuelve las palabras en un flujo expansivo, envolvente, encantatorio: un magma germinal donde el lenguaje recobra su poder genésico.

8.1. Poner entre paréntesis a la conciencia vigilante (policíaca), deformante, inquisidora, forzadora: buscar la verdad intersticial.

8.2. Distracción: défensas, censuras momentảnedmente anuladas: máxima disponibilidad: no resistirse a la revelación excéntrica: "concatena- 
ciones instantáneas y vertiginosas entre cosas heterogéneas": los juegos de la imaginación en sus planos más alucinantes heterogeneidades que se vuelven homogéneas, diversificaciones, que se unifican, analogías de extramuros (externas al tiempo de la ciudad, tiempo de los famas, tiempo de los coleópteros): una convergencia pero siempre inestable, instantánea, precaria.

8.3. Descolocación, desajuste, equivocidad, extrapolación: antropofuguismo: saltos, aletazos zambullidas: ruptura de lo previsible para percibir la flexibilidad y la perneabilidad de to real: volverse "esponja fenoménica".

8.4. Llegar a la desnudez axial para trasponer el umbral de "una realidad sin interposición de mitos, religiones, sistemas y reticulados".

8.5. Romper la malla causal simplificadora; tranquilizadora, acomodaticia: sacar de las casillas: despertar el tiempo anestesiado.

8.6. Disrupción: "Los destiempos y los desespacios que son lo más real de la realidad."

9.1. Realidad: el conjunto de los hechos, de lo verificable: frontera móvil corregida y expandida por el avance del conocimiento.

9.2. Una de las funciones de la imaginación es fabular la realidad futura, aquella que será confirmada por la ciencia.

9.3. No se puede confrontar la literatura con la realidad empírica como referencia fundamental: conírontación que desnaturaliza lo específicamente estético y precaria por la mutación de eso que cómodamente llamamos realidad.

9.4. La ciencia cifra su progreso en la experimentación. La literatura también.

9.5. ¿Por que negar a la literatura la posibilidad de experimentar y congelarla en un realismo servil, reproductor de una versión estereotipada de lo convenido como real? ¿por qué reducir la literatura al papel de comprobante "en segunda instancia de lo real admitido, cuando su función es la de precursora de la futura realidad y compensadora de 12 precariedad de to real? 
9.6. Frente a "una realidad mediatizada y traicionada por los supuestos instrumentos cognoscitivos", Cortázar propone una gnoseologis pótica (en el sentido romántico): videncia, revelación, misterio, incognocibilidad por vía analítico-discursiva: agnosticismo vitalista, demoniaco. Objetivos: preparar al lector, provocar su desprejuiciada disponibilidad (credulidad), acrecentar su porosidad para convertirlo en Todo Uno, en eslabón de la cadena magnética del cosmos.

10.1. Literatura: entretenimiento demoníaco: "excipiente para hacer tragar una gnosis, una praxis o un ethos": literatura instrumental: la escritura es el utensilio para la búsqueda ontológica: la del ser pleno, la del hombre nuevo.

10.2. Cronopio, piantado, camaleón: hombre antiutilitario, antitotalitario, antiburocrático, antidogmático.

10.3. Literatura: nunca mera cocina, cosmética, oficio (artificio): oponerse a la facilidad: subordinar la destreza técnica a pulsiones, impulsos, pasiones: visiones compulsivas: escribir es un acto de amor: "De un cuento así se sale como de un acto de amor, agotado y. fuera del mundo circundante".

10.4 Madurez técnica: maestría al servicio de un verdor candoroso, de una porosidad $y$ disponibilidad infantiles.

10.5. Oficio al servicio: una actividad que no encuentra en si misma su razón de hacerse: no juglaría sino mensajería: no el significante sino el signifiçativo.

10.6. ¿Dos Cortázar?: uno que espera pergreñando páginas intermediarias hasta que se produzca la obertura, el salto metafísico, hasta que aparezca el paracaidas o parasubidas, el extrañamiento exorbitado.

10.7. Cuento: manotazo súbito, antirretórico, estado "ex-orbitado": "una desesperación exaltante, una exaltación desesperada".

10.8. Escritura: impronta rapsódica: desarrollo inspirado, como en el jazz: tensión rítmica, pulsación interna: improvisación reglada: lo imprevisto dentro de parámetros pre-vistos: 12 libertad fatal, ineludible. 
10.9 Lo mejor de la literatura es take: riesgo creador: compromiso total: presente pleno: máxima intensidad.

10.10. Escritura: catapulta para trasponer el espejo (realidad especular, espejismo), para revertir el tapiz (cobertura ilusionista): "porque a mi me funciona la analogía como a Lester el esquema melódico que lo lanzaba al reverso de la alfombra donde los mismos hilos y los mismos colores se transformaban de otra manera."

10.11. Una convicción que comparto: nadie sabe exactamente lo que escribe. Dos interpretaciones posibles: poeta rapsoda-intermediario o tantas lecturas como lectores.

11.1. Cuento: génesis por explosión (cuando la fuerza expansiva es mayor que la de contención), por emergencia aparentemente sủbita: maduración inconsciente: los cuentos caen como cocos sobre la cabeza: "frutos sumamente independientes que crecen solos en las palmetas y se tiran cuando les da la gana".

11.2. Cuento: burbuja llevada a su máxima tensión, a punto de estallar: "cuentos contra el reloj que potencian vertiginosamente un mínimo de elementos".

11.3. A la vez cuentos de génesis lenta, de compleja articulación, de elaboración más minuciosa: Todos los fuegos el fuego, El otro cielo: técnica simultaneista, diacronías que se vuelven sincrónicas, montaje cinemätico, múltiples intentos para abrir la cerrazón formal del cuento.

11.4. El cuento excluye la intervención directa del demiurgo: "que el lector tenga, pueda tener la sensación de que en cierto modo está leyendo algo que ha nacido por sí mismo, en sí mismo y hasta de sí mismo."

11.5. Literatura: desafio: rehuir la facilidad, la seguridad de lo ya probado con éxito: no ceder a la tentadora repetición: salto del cuento a la novela.

12.1. Novela: estructura más abierta: continente más vasto y más plástico: gran totalizadora apta para todo contenido. Género más gnómico: permite a la conciencia reflexiva explicitarse ( $y$ a veces explayar- 
se). El cuento no tolera digresiones, pasajes parásitos, demoras de la acción. En la novela, la meditación, el debate, el esclarecimiento pueden incorporarse a la progresión como activantes: el discurso cognoscitivo puede volverse funcional (Morellianas).

12.2. Novela: literatura más gnómica. Mayor dosis autoexpresiva, autorreferente, autorreflexiva, autobiográfica (Rayuela).

12.3. Novela: multiplicación de las perspectivas que acrecienta las posibilidades intersticiales.

12.4. Apertura y cierre: expansión y contracción como las pulsaciones de un mismo organismo: Diástole: de Los premios a Rayuela [técnica de mosaico, collage (ensamblaje de materiales diferentes que no pierden su alteridad), multiplicidad focal, mayor margen de libertad operativa: lector elector]. Sístole: 62. Modelo para armar [sistema combinatorio más riguroso (simbolización de la figura), dibujo más perfilado, forma más compacta, mejor imbricada, pero semánticamente siempre ambigua, plurivalente]. Diăstole: Libro de Manuel (vuelta al collage, a la diversificación estilística; a mayores desniveles y más polimorfismo).

13.1. Collage: almanaque: La vuelta al mundo en ochenta dias, $U t$ timo rothn: estructura discontinua capaz de incorporar tetazos de todos los discursos posibles: simbolos de la heterogénea y simultánea multiplicidad de lo real.

13.2. Collage: no el edificio clásico (despliegue proporcionado, progresivo, simétrico: metáfora de la armonía universal), sino el laberinto, la ramificación, el jardín de los senderos que se bifurcan.

13.4. Collage: la coexistencia de heterogeneidades como principio de composición. No la homologación, la integración de los materiales en un continuo unificador, la reducción al común denominador, sino la diversidad a veces en bruto: recortes de periódicos, citas, extractos de distintas fuentes letradas e iletradas, incorporados sin reelaboración: discursos, protocolos preexistentes que se juxtaponen con el del autor: discurso polimorfo, plurifocal, politonal.

13.5. Collage: una visión del mundo: imposibilidad de reducir la heterogénea simultaneidad de lo real a canon o norma igualadora: imposible reducir el caos a cosmos. 
13.6. Intertextualidad irreductible a una palabra conciliadora, a la concertación, a la universalidad abstracta del viejo humanismo.

13.7. Oscilación de Cortázar entre heterogeneidad caótica y un principio de concertación sobrehumano: las fuerzas que nos inscriben en ignoradas figuras: "las figuras pavorosas que tejen en la sombra las grandes Madres".

14.1. Relación vital entre autor y obra: relación visceral, sanguínea, glandular: la vida es la fuerza transmisora que conecta todas las instancias del proceso (de la emisión a la recepción del mensaje). Vida: animación biológica, la suma de lo experimentado, el complejo de lo vivido en bloque, como organismo no desmontable.

14.2 Identificación vital del narrador con sus personajes: cordón umbilical ramificado o cordones al por mayor.

14.3. Libros fraternalmente incitadores, provocadores; conmovedores: libro-abrazo: librazo.

14.3. Libro entrañable: despertador de "un eco vital, una confirmación de latencias, de vislumbres, de aperturas hacia el misterio y la extrañeza y la gran hermosura de la vida."

14.5. "De mi país se alejó un escritor para quien la realidad, como la imaginaba Mallarmé, debía culminar en un libro; en París nació un hombre para quien los libros deberán culminar en la realidad."

14.6 Objetivos vitales $=$ objetivos textuales. Obra $=$ conducta. Modo de escribir: modo de vivir: escribir lo vivido y vivir lo escrito: escribir lo vivible.

14.7. Relación vital: relación generadora de insatisfacción, de desajuste. Lo escrito por la imaginación en libre juego (sin las ataduras de lo real verificable y practicable) precede y supera a lo vivido: dificultad de vivir lo escrito.

14.8. Cortázar: literatura empedernidamente axiológica: desesperada y contradictoriamente propone cánones de conducta, emite juicios de valor, da direcciones morales. Rayuela: proposiciones (alusivas, figuradas, metafóricas, expresas) para un humanismo liberador. 
14.9. Contrapartida: liberación total implica también liberación del mal, abrir la caja de Pandora: liberación de instintos destructivos, de fuerzas aniquiladoras. Mal, caos, entropía, muerte, dispersión, disolución, caída, vacío: la perpetua presencia amenazante a la que no siempre puede rehuirse por el salto imaginativo, el vuelo evasivo, la ilusión poética: fracaso de Oliveira.

14.10. Libertad acrecentada e ilusión de libertad: destino decidido por las Hilanderas que urden esas tramas en las que somos un hilo entrecruzado, anudado, tenue, intermitente.

14.11. Liberación total: liberarse de las contingencias: liberarse de la historia: liberarse de la especie: "Un hombre debería ser capaz de aislarse de la especie dentro de la especie misma, y optar por el perro o el pez original como punto inicial de la marcha hacia sí mismo."

15.1. Imposibilidad de eludir el condicionamiento histórico: "En to más gratuito que pueda yo escribir asomará siempre una voluntad de contacto con el presente histórico del hombre". Historicismo tácito pero no determinismo histórico: partir de la determinación histórica para superarla.

15.2. Escribir históricamente: ¿escribir la historia?: no, escribir en la historia: inscribirse en la historia.

15.3. Orientarse hacia "una trascendencia en cuyo término esté esperando el hombre": la trascendencia del arte que involucra su época para sobrevivirla: trascender lo literario: "Contar sin cocina, sin maquillaje, sin guiñadas de ojo al lector": desnudarse: "De golpe las palabras, toda una lengua, la superestructura de un estilo, una semántica, una psicologia y una facticidad se precipitan en espeluznantes harakiris": bañarse en los ríos metafísicos: regresión a lo preformal, regeneración, nuevo nacimiento: siempre el mitema arquetípico.

15.4. El condicionamiento histórico: autor representativo de su época: los jóvenes de América encuentran en Cortázar su portavoz, su intérprete: Cortázar expresa, figura, simboliza el mundo por ellos deseado: abolición imaginaria (ficción narrativa) de las restricciones de la realidad empirica. 
15.5 Cortázar significa valores (tendencias, preponderancias, elecciones, pasiones, pulsiones, repulsiones) de su época: valores que cuentan con la adhesión sentimental de multitud de lectores: valores realizables e irrealizables: más que prácticas o realidades fácticas son proyecciones liberadores y compensatorias de la represión realista.

16.1. Tendencia metafísico-estética y compromiso político. Catalizador: la Revolución Cubana: la vislumbre de un socialismo capaz de devolver al hombre la plenitud de su condición humana.

16.2. Revolución: tiempo abierto, tiempo esponja, edad porosa. Proyecto utópico: " $\mathrm{L}$ a revolución será permanente, contradictoria, imprevisible, o no será."

16.3 Identificación de vanguardia y retaguardia políticas con vanguardia y retaguardia estéticas: "La colonización, la miseria y el gorilato también nos mutilan estéticamente": abolir las opresiones político-sociales es abolir las estéticas.

16.4. Papel transformador de las minorías esclarecidas: rebelión de los adelantados (vanguardia revolucionaria) como detonador de la rebelión generalizada: París, mayo del 68 .

17.1 Visión totalizadora de la historia y de la cultura: empedernido cosmopolitismo: expatriado, poligloto, lector y escritor del más amplio espectro cultural, pertinaz explorador del planeta: circulación permanente por todos los tiempos y lugares: perpetuo itinerante nunca anclado ni aquietado.

17.2. Argentinismo tácito, antinacionalista ("nacionalistas de escarapela y banderita"): argentinismo sustancial como conformación básica, no como autoctonía restrictiva ("telurismo estrecho, partoquial, aldeano").

17.3. Americanismo (como el del Che): voluntad de asumir la condición de intelectual del tercer mundo. $\mathrm{L}_{\mathrm{a}}$ escala continental conviene más a su vocación ecuménica, a su expansiva apetencia de apertura.

17.4. Escribir para propio deleite o tormento sin concesiones ni obligaciones latinoamericanas o socialistas consideradas como presupuestos pragmáticos. 
17.5. "Rayuela, un problema metafísico, un desgarramiento continuo entre el monstruoso error de ser lo que somos como individuos y como pueblos en este siglo, y la entrevisión de un futuro en el que la sociedad humana culminaria por fin en ese arquetipo del que el socialismo da una visión práctica y la poesía una visión espiritual."

. 18.1. Personalidad camaleónica: conocer sin identidad: anegarse en la realidad sin consignas: Cortázar: proteico, imprevisible, contradictorio, metamórfico: un mutante que ha cambiado varias veces de existencia.

18.2. Conciencia conflictiva, desgarrada: como en todo intelectual actual: discordia inconciliable entre deseo y realidad, entre querencia, apetencia y posesión, entre lo buscado y lo dado, entre el anhelo de liberación, renovación, revolución y la resistencia atroz de un mundo cada vez más destructivo, más opresor, más inhabitable. El pago de la lucidez: desasosiego; el pago de la honradez: permanente desajuste.

18.3. Logros: textos magistrales: posesiones fulgurantes, inscriptas: intermitencias de esplendor, registradas: manotazos y roces solares, escriturados: un decir duradero, empuñado: varios rounds a favor: pelea ganada.

SaÚl YuRkievich

Université de Paris,

Vincennes 